\title{
A linguagem do poder e o poder da linguagem: Lima Barreto e a Língua Portuguesa
}

\author{
Maurício Silva \\ Universidade Santo Amaro
}

\section{Abstract}

The present article analyses the linguistic ideology of Lima Barreto's fiction and literary criticism, through a metalinguistic discourse. In fact the linguistic perspective reveals the powerful dimension of the language, and Lima Barreto makes use of this power in order to fight against social and linguistic prejudice.

Adopting both the Discourse Analysis and Linguistic Historiography methodologies, this article is concerned with academic style, linguistic purism and grammatical preciosity in the premodernist language. 


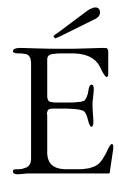

inegável que o século XIX - sobretudo sua segunda metade - marca um avanço considerável nos estudos destinados à análise da Língua Portuguesa em geral e, particularmente, de sua relação com a realidade cultural brasileira. De lá para cá, são inúmeros os autores que se dedicaram, em maior ou menor grau, a abordagens inéditas de fatos da língua que resultaram de um indefectível processo de aclimatação do português no Brasil, autores que vão das figuras intelectualmente ecléticas de um Rui Barbosa e um João Ribeiro a personalidades eminentes dos estudos lingüísticos, como um Celso Cunha ou um Mattoso Camara, para citar apenas alguns dos muitos estudiosos dessa questão.

Mas há também aqueles que, sem se caracterizar necessariamente como intelectuais de destaque e sem poderem ser considerados especialistas de nossos fatos da linguagem, também deram uma importante contribuição ao estudo e desenvolvimento da Língua Portuguesa no Brasil. Em geral, trata-se de escritores mais dedicados à arte da ficção do que propriamente à ciência da linguagem; e que, de uma forma ou de outra, procuraram expor, nem sempre com a esperada isenção, sua valiosa opinião a respeito de tão delicado assunto: basta, para tanto, que nos lembremos de algumas querelas lingüísticas em que se envolveram um José de Alencar, um Affonso de Taunay ou um Júlio Ribeiro. Sem ter relação direta com contendas dessa natureza, questões relativas ao emprego da Língua Portuguesa no Brasil podem ser encontradas ainda em escritores como Monteiro Lobato, Mário de Andrade, Coelho Neto ou Gonçalves Dias, todos romancistas e poetas de renome.

Entre tantos literatos preocupados com a utilização e o desenvolvimento de nossa língua, podemos destacar a figura de Lima 
Barreto, romancista que soube como poucos empregar sua pena em favor de uma série de questões sociais, mas que também se voltou com desusada pertinácia para a problemática do português, principalmente seu funcionamento dentro do discurso literário. Se atentarmos para as relações possíveis entre a produção literária (mas também a jornalística e epistolar) de Lima Barreto e a Língua Portuguesa, perceberemos que é possível compreender as mesmas pelo menos sob dois pontos de vista: de um lado, no que se refere à práxis literária do romancista carioca, pode-se tentar estudar - sob vários aspectos - a concretização de idéias lingüísticas na ficção limabarretiana, trabalho aliás já realizado em diversos momentos de nossos estudos críticos $;^{1}$ de outro lado, no que diz respeito a formulações teóricas da linguagem, pode-se tentar depreender a formação de um ideário lingüístico de Lima Barreto a partir da abordagem do discurso metalingüístico empregado pelo mesmo. Tal abordagem, feita apenas esporadicamente por alguns estudiosos do romancista e, ainda assim, sem nenhuma sistematização analítica, é o propósito principal deste ensaio.

Já pela definição de nosso propósito, não é difícil perceber que tal estudo encontra na intersecção interdisciplinar entre literatura e lingüística seu fundamento metodológico genérico. Especificamente, contudo, a base teórica do mesmo apoiar-se-á na Historiografia Lingüística, enfatizando a história externa da língua a partir da perspectiva limabarretiana (ideário lingüístico), e, tangencialmente, em alguns pressupostos teóricos estabelecidos pela Análise do Discurso, mas apenas na medida em que esta nos permite observar os posicionamentos explícitos de Lima Barreto (discurso metalingüístico) diante dos problemas relacionados ao emprego da língua na produção ficcional (discurso literário).

Com efeito, o próprio fato de buscarmos situar o ideário lingüístico do romancista carioca, no que diz respeito aos estudos da linguagem, no contexto de sua época, já pressupõe uma abordagem historiográfica desse assunto, uma vez que há, nesse sentido, uma valorização da perspectiva externa da língua, tal como 
propõe a própria Historiografia Lingüística. ${ }^{2}$ Por outro lado, não nos podemos esquecer de que, como sugerem algumas práticas estabelecidas pela Análise do Discurso, é possível atingir - por meio dessa outra abordagem - questões que, na aparência, são puramente lingüísticas, mas na verdade extrapolam tal perspectiva, já que a lingüística do discurso esforça-se "para escapar da dupla redução da linguagem à língua, objeto ideologicamente neutro, e ao código, com função puramente informativa", tentando "reintroduzir o sujeito e a situação de comunicação" na discussão lingüística. ${ }^{3}$ O sujeito, no caso, é o próprio Lima Barreto enquanto produtor de discursos que, a um só tempo, manifestam um posicionamento político explícito do romancista e, pela fatura literária, concretiza esse mesmo posicionamento.

\section{IDEÁRIO LINGÜÍSTICO E DISCURSO}

Sabemos que o começo do século foi uma época de particular efervescência gramatical (o termo é de Cavalcanti Proença), em que a expressão lingüística sofria intensa pressão dos guardiães da Língua Portuguesa, a todo instante prontos para apontar eventuais falhas gramaticais, que iam da grafia incorreta de um vocábulo à colocação inadequada de um pronome. Se fôssemos, contudo, analisar mais detidamente o contexto lingüístico em que Lima Barreto viveu e produziu suas obras, não seria difícil perceber a presença de uma dicotomia quase indissolúvel entre o conservadorismo e a renovação lingüísticos, fazendo com que o emprego da Língua Portuguesa no âmbito ficcional oscilasse entre a inovação e a manutenção de um determinado padrão da língua. ${ }^{4}$

Nesse sentido, podemos dizer que a manutenção de um padrão lingüístico culto ficava também, mas não exclusivamente, a cargo da Academia Brasileira de Letras, entidade que nasce sob os auspícios de uma ideologia lingüística particularmente conservadora: trata-se de uma instituição que tinha prescrito em seus estatutos a preservação da "cultura da língua e da literatura nacional". 5 É emblemática, 
nesse sentido, a passagem em que Coelho Neto - ao saudar, num discurso realizado na mesma Academia em 1926, o estudioso francês Paul Hazard - afirma:

\begin{abstract}
"A Academia Brasileira de Letras é a séde onde se cultiva a língua nacional (...) A linguagem, vós bem o sabeis, Sr. Professor, e prégais, é a Religião da Pátria (...) A nossa tem nesta Casa umas das suas officinas de depuração e polimento. Aqui é ella pacientemente trabalhada, joeirada, lapidada e conservada". ${ }^{6}$
\end{abstract}

Já a renovação do discurso literário/ficcional ficava por conta de uma série de autores mais ou menos marginais à estética literária prevalente: são os chamados pré-modernistas, dos quais Lima Barreto pode ser considerado uma das principais figuras.

O romancista carioca revela-se, desde o princípio, um autor particularmente sensível ao poder coercitivo da linguagem culta, o que o levaria a se afirmar como um escritor que fez do desvio da norma lingüística vigente uma de suas principais bandeiras estéticas. No seu caso, portanto, tal desvio não se manifesta como uma atitude acomodada de isolamento diante de um fato contra o qual seria aparentemente inútil lutar, mas antes como uma práxis literária norteada pelo combate fervoroso contra toda forma de dominação lingüística. É nesse instante que Lima Barreto empunha suas armas e sai a campo contra o poder lingüístico constituído sob a forma de correção de linguagem, opondo-se visceralmente a pelo menos três categorias conceituais articuladas à questão da língua: o preciosismo gramatical, o purismo lingüístico e o academicismo estilístico.

No que diz respeito ao preciosismo gramatical, podemos afirmar sem receio que este foi um dos temas mais caros à pena engajada de Lima Barreto e uma de suas mais obsedantes lutas. Perseguido pelos gramáticos, que insistiam em apontar incorreções em seus escritos, Lima Barreto parecia agir ora com desprezo, ora com ironia, diante dos ataques sofridos. É certo que, muitas vezes, essa atitude mais parecia despeito, traduzido em passagens confessionais que facilmente nos deixam desconfiados de sua sinceridade e isenção. Enfatizava assim, com duvidosa insistência, 
seu desprezo pelas críticas sofridas, como numa de suas cartas ao amigo Lucilo Varejão, em que afirma:

"eu temo tanto esses tais clássicos e sabedores de gramática como
a qualquer toco de pau podre por aí (...) Meus livros saem errados
devido à minha negligência e ao meu relaxamento, à minha letra,
aos meus péssimos revisores, inclusive eu mesmo. Isso explica os
erros vulgares; mas, quanto aos outros da transcendente gramática
dos importantes, eu nunca me incomodei com eles".

Em outra passagem semelhante, volta a insistir:

"Não me preocupo com essas cousas transcendentes de gramática e deixo a minha atividade mental vagabundear pelas ninharias do destino da Arte e das categorias do pensamento". ${ }^{7}$

Tais afirmações soam algo falsas diante de algumas passagens - sintomaticamente presentes em seu Diário Íntimo - em que o romancista, ao contrário do que acabara de dizer, revela uma relativa preocupação com essas transcendências gramaticais, como no trecho em que, ao comentar uma frase de Gilberto Amado ("como é que eu poderei mandar ao meu amigo coisas que o desagradam”), afirma:

"desagradar é verbo intransitivo. Pede, portanto, objeto indireto. É o mais grave êrro do artigo, pois o pronome devia ser "lhe" e não "o". Que clássico! Todos são assim. Quanto mais falam em gramática, mais erram por conta própria". 8

Mas, via de regra, o romancista carioca parecia ter bastante razão em seus ataques, e o que acaba prevalecendo mesmo é uma atitude acidamente irônica em relação ao preciosismo gramatical de seus contemporâneos.

Um exemplo dessa atitude é o tratamento que Lima Barreto dá a algumas de suas personagens, particularmente os gramáticos, ridicularizados com freqüência pelo romancista, como no caso do Capitão Pelino, mestre-escola e redator de jornal no conto A Nova Califórnia: desfrutando a fama de sábio pelo mero fato de ser um 
gramático, atuava como uma espécie de censor da língua, promovendo um verdadeiro "apostulado do vernaculismo"; ou no caso do Doutor Barrado, no conto Como o "Homem" chegou: trata-se, aqui, de uma personagem, segundo as palavras do romancista, de "pichoso saber gramatical", inconformado com as colocações lingüísticas pouco puristas. ${ }^{?}$

Mas o melhor exemplo, nesse aspecto, é o de Lobo Neves, nas Recordações do Escrivão Isaías Caminha: gramático do jornal $O$ Globo, obsessivamente preocupado com a correção gramatical - mas uma correção que tem como referência o mais castiço emprego da língua -, Lobo Neves acaba louco e internado no hospício, de tanto ouvir o que considerava impropriedades lingüísticas; no hospício, passa o tempo lendo e recitando a Ensynança de Bem Cavalgar, de Dom Duarte, e tapando os ouvidos para não ouvir nada; na redação do jornal, tinha fama de caturra e mal humorado, sempre às voltas com as regras gramaticais e à procura de colocações que destoavam do rígido saber lingüístico. Numa passagem em que procura descrever a figura de Lobo Neves, podemos entrever a idéia que o próprio Lima Barreto fazia da gramática:

"A Gramática do velho professor era de miopia exagerada (...) Não admitia equivalências, variantes; era um código tirânico, uma espécie de colete de força em que vestira as suas pobres idéias e queria vestir as dos outros. Há três ou cinco gramáticas portuguesas, porque há três ou cinco opiniões sobre uma mesma matéria". ${ }^{10}$

A partir desse entrecho, podemos concluir que, para Lima Barreto, o emprego da linguagem requer, antes de mais nada, uma relativa flexibilidade, um reconhecimento de equivalências e variantes, numa clara percepção de fatos lingüísticos que só seriam unanimemente aceitos quase meio século depois, com os irretorquíveis avanços da Sociolingüística.

Posicionamentos como esse podem ser verificados na própria práxis literária do romancista carioca, a começar pelo seu célebre desleixo, o qual é objeto de inúmeras interpretações, sendo a mais aceita aquela que vê neste seu desapego à gramática uma atuação 
deliberada, no sentido de combater os cânones gramaticais da época e se destacar pela diferença, e, não, pela similitude lingüística. Assim, podemos afirmar sem rebuços que Lima Barreto coloca-se, na sua época, como um defensor exaltado de uma liberdade gramatical relativa.

Conceito muito próximo do de preciosismo gramatical, o purismo lingüistico assume um feitio um pouco mais generalizante: enquanto aquele pode ser entendido como uma utilização rebuscada/ preciosista da língua, esta pode-se referir ao emprego da linguagem a partir de preceitos gramaticais rigorosamente definidos (norma).

A questão é que Lima Barreto devotava um particular desprezo e articulava um obstinado combate contra todos aqueles que, de um modo ou de outro, procuravam ditar regras para um pretenso bom uso da linguagem. Nesse sentido, Lima Barreto pode ser considerado a primeira dissidência e resistência ao purismo prevalente na passagem do século, representado por uma série de escritores acadêmicos que faziam da linguagem castiça e elegante um verdadeiro dogma literário. ${ }^{11}$

É nesse sentido, portanto, que podemos entender os inúmeros ataques de Lima Barreto àqueles pseudo-intelectuais mais preocupados em revestir suas parcas idéias com uma linguagem pretensamente escorreita do que veicular valores verdadeiramente relevantes: é a esses escritores de muita forma e pouco fundo-demasiadamente literários como diria José Veríssimo ${ }^{12}$ - que o romancista carioca devota especial desprezo, como comprovam estas palavras particularmente confessionais do mesmo:

"por toda a parte tenho mostrado a minha insurreição contra o clichê grego e sempre que posso desanco a cacetado dos clássicos portugueses que os médicos literatos nos querem impingir como modelos de bela linguagem". ${ }^{13}$

Parece não ter havido nada mais ofensivo, mais exasperador para Lima Barreto do que essas infrutíferas tentativas de domar a língua literária, atitude que ele não ousou atacar em mais de uma oportunidade. Para Lima Barreto, a boa linguagem, na verdade, era 
aquela que conseguisse, com simplicidade e clareza, transmitir idéias profundas, de preferência de cunho marcadamente social, como o autor defendeu na teoria e realizou na prática. E idéias profundas só poderiam ser vazadas, no seu ponto de vista, por meio de uma expressão particularmente modesta.

Por estas e outras razões, Lima Barreto busca atacar, não poucas vezes, esse tipo de linguagem que pouco tem a ver com a realidade lingüística de um povo, na sua maioria, iletrado e de um país ainda à procura de uma expressão literária própria e independente. Aludindo alegoricamente à nossa língua, em Os Bruzundangas, Lima Barreto deixa clara essa sua posição pouco condescendente:

"aquela (linguagem) em que escreviam os literatos importantes, solenes, respeitados, nunca consegui entender, porque redigem eles as suas obras, ou antes, os seus livros, em outra muito diferente da usual, outra essa que consideram como sendo a verdadeira, a lídima, justificando isso por ter feição antiga de dous séculos ou três". ${ }^{14}$

Posicionamentos intransigentes e nada conciliatórios, como os citados, podem ser encontrados ainda no tratamento dado pelo romancista à noção de academicismo estilístico. Aqui, tal conceito perde sua significação mais propriamente literária, para revestir-se de um sentido mais ligado à idéia de expressão lingüistica destinada a uma finalidade artística. O academicismo estilístico, nesse sentido, não era senão aquela linguagem de que se serviam os escritores particularmente preocupados em manter a literatura numa espécie de camisa-de-força lingüística: uma expressão rebuscada, excessivamente vernacular, de claros contornos parnasianos e sobretudo conservadora. Enfim, uma linguagem acadêmica.

Desse modo, Lima Barreto coloca sob suspeição a validade da linguagem imposta pela tradição acadêmica, que acaba por falsear a realidade, e dá um passo decisivo em direção à estética modernista, a qual vingaria anos mais tarde: "a primeira forma de recusa de compromisso com a elite intelectual se faz pela denúncia da escrita academicista, velha, coelhonetista, numa ruptura que antecipa a instauração do novo na escrita modernista". ${ }^{15}$ 
Sua luta, nesse contexto, volta-se contra o linguajar clássico, empregado por aqueles que, segundo o autor, buscam de algum modo ludibriar o interlocutor: combate, portanto, toda forma de "arcaísmos de léxico e de sintaxe" ou a mescla de "vocábulos, modismos, construções, idiotismos" de séculos diferentes num mesmo período, procedimentos que considera próprio do "estilo clássico". ${ }^{16}$

Mas se os exemplos acima arrolados ilustram o infatigável combate de Lima Barreto contra uma série de fenômenos da linguagem, cumpriria perguntar, a estas alturas, quais teriam sido as saídas encontradas pelo célebre romancista, quais as suas propostas para reverter o quadro apresentado. Se seu inusitado engajamento literário pressupunha uma série de batalhas contra o que considerava lingüisticamente espúrio e ilegítimo, é natural que buscasse soluções para os problemas apontados e indicasse caminhos a serem trilhados nessa árdua tarefa de construção de uma expressão lingüística autenticamente brasileira.

Uma das saídas propostas por Lima Barreto, por contraditório que pareça, tem seu fundamento exatamente na revalorização de uma tradição lingüística. Evidentemente, não se trata aqui de um sentido clássico de tradição, isto é, um conjunto de procedimentos virtualmente legados a gerações posteriores, o que corresponderia à defesa de uma linguagem de natureza arcaizante. Ao contrário, sua concepção de tradição sugere antes duas idéias, a nosso ver, bastante originais e ousadas para a época em que o autor viveu e escreveu: em primeiro lugar, Lima Barreto busca uma saída na idéia de recuperação de um discurso fundador de nossa nacionalidade, o que, no limite, pode ser entendido tanto como uma tentativa utópica de ressurgimento do tupi-guarani quanto como a defesa de uma linguagem verdadeiramente abrasileirada, em que se destaca uma luta acirrada contra a dicção e o estilo lusitanizantes. Particularmente no primeiro caso, destaca-se a célebre proposta apresentada por Policarpo Quaresma à Câmara Municipal, em que o protagonista não hesita em aliar política e idioma: 
"Policarpo Quaresma, cidadão brasileiro, funcionário público, certo de que a lingua portuguesa é emprestada ao Brasil; certo também de que, por esse fato, o falar e o escrever em geral, sobretudo no campo das letras, se vêem na humilhante contingência de sofrer continuamente censuras ásperas dos proprietários da língua; sabendo, além, que, dentro do nosso país, os autores e os escritores, com especialidade os gramáticos, não se entendem no tocante à correção gramatical, vendo-se, diariamente, surgir azedas polêmicas entre os mais profundos estudiosos do nosso idioma - usando do direito que lhe confere a Constituição, vem pedir que o Congresso Nacional decrete o tupi-guarani, como lingua oficial e nacional do povo brasileiro (...) O suplicante, deixando de parte os argumentos históricos que militam em favor de sua idéia, pede vênia para lembrar que a lingua é a mais alta manifestação de inteligência de um povo, é a sua criação mais viva e original; e, portanto, a emancipação política do país requer como complemento e conseqüência a sua emancipação idiomática". ${ }^{17}$

Fica clara, nesse trecho da petição de Policarpo Quaresma, sua intenção de retomar uma discussão candente em torno da problemática lingüística, ora atacando os gramáticos, ora colocando sob suspeição o papel da Língua Portuguesa como representante autêntico da nação brasileira, ora buscando aliar de modo indelével os conceitos de independência política e emancipação idiomática. É essa tentativa de evitar o apagamento do tupi na tradição cultural brasileira que caracteriza o discurso fundador limabarretiano. ${ }^{18}$

Em segundo lugar, o romancista busca uma saída na idéia de liberdade lingüística, portanto, na defesa contínua de uma linguagem popular, uma linguagem que tivesse como uma das principais marcas não apenas a dicção nacional, mas ainda uma estrutura gramatical condizente com o nosso falar. Nesse sentido, Lima Barreto parecia estar completamente de acordo com algumas tendências lingüísticas de sua época, já que, desde o final do século XIX, uma das características da questão idiomática foi o êxito na abertura de um caminho próprio para a consolidação de uma gramática com características lingüísticas brasileiras. ${ }^{19}$ Seus escritos, nesse sentido, estão recheados de colocações sintático-morfológicas e de diálogos próprios de uma proposta lingüística - o que implica uma práxis 
literária - deliberadamente renovadora: invertendo e renovando um paradigma caro aos gramáticos mais conservadores e tradicionalistas (para quem o uso lingüístico deve acompanhar rigidamente os preceitos normativos), Lima Barreto propõe não apenas o estabelecimento de uma norma que tenha como referência o uso, mas, mais do que isso, que tenha como referência o uso popular.

\section{CONCLUSÃO}

A luta de Lima Barreto contra os cânones lingüísticos de sua época representam um primeiro passo rumo às conquistas modernistas no campo da linguagem, já que o romancista carioca inaugura não apenas um discurso de contestação dos preceitos lingüísticos sustentados pela Academia, mas também ensaia uma prática literária que, incontestavelmente, irá abrir caminho para a longa marcha rebelde e iconoclasta dos primeiros modernistas. Nesse sentido, Lima Barreto pode ser considerado um autêntico autor pré-modernista, título que nem mesmo os mais empertigados revolucionários da Semana de 22 ousaram retirar dele. ${ }^{20}$

Não obstante, essa propensão de Lima Barreto à destruição de mitos lingüísticos, suas propostas nesse campo possuem um forte apelo nacionalista, fazendo com que o mesmo seja, compulsoriamente, inserido na ampla discussão em torno do emprego da Língua Portuguesa no Brasil da época; uma discussão que envolveria nomes tão diferentes como um João Ribeiro ( A Lingua Nacional), Mário de Andrade (Gramatiquinha) ou Xavier Marques (Cultura da Lingua Nacional). Nesse contexto, a figura de Lima Barreto se destaca exatamente por se tratar de um autor que, sem ser especialista no assunto, logrou antecipar - prática e teoricamente - uma série de questões polêmicas que seriam, logo em seguida, aprofundadas e, não poucas vezes, levadas ao paroxismo.

Como sugeriu Ledo Ivo em seu arguto estudo, Lima Barreto

"demonstrou que o domínio de certos homens sobre os seus semelhantes se processa através da diferenciação lingüística e da lei gramatical (...) examinou e interrogou o problema da linguagem e 
da gramática tornadas instrumentos de classe, de repressão e opressão, e destinadas a não permitir que os homens se exprimam plenamente, e convivam harmoniosamente, mas a impedir que o façam". ${ }^{21}$

Para Lima Barreto, portanto, a língua se afirma como uma incontestável expressão do poder constituído, daí a possibilidade de o romancista carioca, ao se colocar numa posição contrária à doutrina lingüística oficial, estar na verdade desempenhando seu papel de escritor-militante na luta contra o establishment político republicano das primeiras décadas do século. Assim, ao empregar uma linguagem marcada pelo desleixo intencional, Lima Barreto estaria indo não apenas contra tudo aquilo que a estética oficial representava, mas principalmente contra o poder político-social que essa retórica simbolizava de modo tão substantivo.

\section{NOTAS}

${ }^{1}$ Consultar, por exemplo, estudos a respeito do diálogo em Lima Barreto (PRETI, Dino. Sociolingüistica. Os Niveis de Fala. Um Estudo Sociolingüistico do Diálogo na Literatura Brasileira. São Paulo, Companhia Editora Nacional, 1987); da gramática (NADÓLSKIS, Hêndricas. A Lingua Literária de Lima Barreto: Traços Distintivos. São Paulo, FFLCH/USP, 1989, Tese de Doutorado); ou do estilo (PROENÇA, M. Cavalcanti. "Lima Barreto". Augusto dos Anjos e Outros Ensaios. Rio de Janeiro, José Olympio, 1959, p.37-82).

${ }^{2}$ Cf. SWIGGERS, Pierre. "History of Linguistics". In: BRIGHT, William (ed.). International Encyclopedia of Linguistics. Oxford, Oxford University Press, 1992, Vol. 2, p.140-141; SWIGGERS, Pierre. "L'Historiographie des Sciences du Langage: Intérêts et Programmes". Proceedings of the Fourteenth International Congress of Linguists. Berlin, Akademie-Verlag Berlin, 1987, Vol III, p.2713-2715; SWIGGERS, Pierre. "Reflections on (Modelos for) Linguistic Historiography". Understanding the Hisoriography of Linguistics. Problems and Projects. Münster, Hüllen, 1990, p.21-34; e KOERNER, Konrad. "Questões que persistem em Historiografia Lingüística". Revista da Anpoll, Universidade de São Paulo, São Paulo, No. 02: 4570, 1996. 
${ }^{3}$ MALDIDIER, Denise et Alii. "Discurso e Ideologia: Bases para uma Pesquisa". In: ORLANDI, Eni Puccinelli (org.). Gestos de Leitura. Da História no Discurso. Campinas, Unicamp, 1994, p.67-102. Cf. também GADET, Françoise e HAK, Tony (orgs). Por uma Análise Automática do Discurso. Uma Introdução à Obra de Michel Pêcheux. Campinas, Unicamp, 1993.

${ }^{4}$ Cf. MARTINS, Nilce Sant'Anna. História da Língua Portuguesa. Século XIX. São Paulo, Ática, 1988; e PINTO, Edith Pimentel. História da Lingua Portuguesa. Século XX. São Paulo, Ática, 1988.

${ }^{5}$ PEIXOTO, Afrânio et Alii. "Estatutos e Novo Regimento Interno da Academia Brasileira". Revista da Academia Brasileira de Letras. Rio de Janeiro, Vol XIII, No. 25-26: 05-22, Jan./Jun. 1923. Consultar também, para essa questão, GALVÃO, Francisco. A Academia de Letras na Intimidade. Rio de Janeiro, A Noite, 1937; e NEVES, Fernão. A Academia Brasileira de Letras. Notas e Documentos para a sua História (1896-1940). Rio de Janeiro, Publicações da Academia Brasileira, 1940.

${ }^{6}$ NETO, Coelho. Livro de Prata. São Paulo, Livraria Liberdade, 1928, p.158.

${ }^{7}$ Respectivamente: BARRETO, Lima. Correspondência. São Paulo, Brasiliense, Tomo II, 1956, p.226; e BARRETO, Lima. Impressões de Leitura. São Paulo, Brasiliense, 1956, p.86.

${ }^{8}$ BARRETO, Lima. Diário Íntimo. Rio de Janeiro, Mérito, 1953, p.116.

9 Ambos os contos encontram-se em BARRETO, Lima. Clara dos Anjos. Rio de Janeiro, Mérito, 1948.

${ }^{10}$ BARRETO, Lima. Recordações do Escrivão Isaías Caminha. São Paulo, Ática, 1984, p.113.

${ }^{11}$ Para uma leitura de Lima Barreto como dissidência/resistência ao purismo lingüístico, consultar LEITE, Marli Quadros. O Purismo Lingüístico. Suas Manifestações no Brasil. São Paulo, FFLCH, 1996 (tese de doutorado). E para considerações gerais a respeito do purismo lingüístico relacionado à Língua Portuguesa, consultar CUNHA, Celso. Língua Portuguesa e Realidade Brasileira. Rio de Janeiro, Tempo Brasileiro, 1986.

${ }^{12}$ Cf. VERÍSSIMO, José. Letras e Literatos. Estudinhos Críticos da Nossa Literatura do Dia. 1912-1914. Rio de Janeiro, José Olympio, 1936.

13 BARRETO, Lima. Impressões de Leitura, p.200.

${ }^{14}$ BARRETO, Lima. Os Bruzundangas. São Paulo, Ática, 1985, p.19.

${ }^{15}$ RESENDE, Beatriz. "Lima Barreto: A Opção pela Marginália”. In: SCHWARZ, Roberto (org.). Os Pobres na Literatura Brasileira, p.75. Sobre a questão do antiacademicismo de Lima Barreto, consultar também PRADO, Antonio Arnoni. Lima Barreto: O Crítico e a Crise. Rio de Janeiro, Cátedra/Brasília, INL, 1976. 
${ }^{16}$ BARRETO, Lima. Feiras e Mafuás. São Paulo, Brasiliense, 1956, p. 100.

${ }^{17}$ BARRETO, Lima. Triste Fim de Policarpo Quaresma. São Paulo, Ática, 1987, p.48 (grifos nossos).

${ }^{18}$ Sobre a questão do discurso fundador relacionado ao apagamento do tupi no Brasil, de uma perspectiva lingüístico-discursiva, consultar ORLANDI, Eni Pulcinelli. Terra à Vista. Discurso do Confronto: Velho e Novo Mundo. São Paulo/ Campinas, Cortez/Unicamp, 1990.

${ }^{19}$ Cf. TARALLO, Fernando. "Diagnosticando uma Gramática Brasileira: o Português d'aquém e d'além-mar ao Final do Século XIX”. In: ROBERTS, Ian e KATO, Mary A. (orgs). Português Brasileiro. Uma Viagem Diacrônica. Campinas, Unicamp, 1993, p.69-105.

${ }^{20}$ As recusas e ataques feitos a Lima Barreto no calor da hora modernista foram, posteriormente, revistas pelos autores da Semana (cf. MILLIET, Sérgio. "Setembro, 17”. Diário Crítico de Sérgio Milliet. São Paulo, Martins/Edusp, 1981, Vol. VIII, p.244-248).

${ }^{21}$ IVO, Lêdo. "Lima Barreto: A Autoridade do Malogro". A Ética da Aventura. Rio de Janeiro, Francisco Alves, 1992, p.17-28.. 